\title{
Artigo/Articles
}

\section{A análise de atividade e a construção do olhar do terapeuta ocupacional*}

\section{Activity analyses and the perception of the occupational therapist}

\author{
Elizabeth M. F. Araújo Lima ${ }^{1}$
}

LIMA, E. M. F. A. A análise de atividade e a construção do olhar do terapeuta ocupacional. Rev. Ter. Ocup. Univ. São Paulo, v. 15, n. 2, p. 42-8, maio/ago., 2004.

RESUMO: Este artigo tem por objetivo discutir a análise de atividades no campo da Terapia Ocupacional, considerando este procedimento como uma estratégia de construção do olhar do terapeuta ocupacional, voltado para a ação humana e para os sujeitos em atividade.

DESCRITORES: Terapia Ocupacional/tendências. Percepção. Atividades humanas.

\footnotetext{
* Este texto foi originalmente elaborado para utilização como texto didático na disciplina Atividades e Recursos Terapêuticos: repertório de atividades, do Curso de Terapia Ocupacional da FMUSP (1998) e foi re-trabalhado para publicação.

${ }^{1}$ Docente do Curso de Terapia Ocupacional do Departamento de Fisioterapia, Fonoaudiologia e Terapia Ocupacional da FMUSP. Doutora em Psicologia Clínica pelo Programa de Estudos Pós-Graduados em Psicologia Clínica da PUC-SP. Membro do Laboratório de Estudos e Pesquisa Arte e Corpo em Terapia Ocupacional.

Endereço para correspondência: Rua Min. Américo Marco Antônio, 351. São Paulo, SP. CEP: 05442-040. e-mail: elizabeth.lima@uol.com.br
} 


\section{INTRODUÇÃO}

$\mathrm{N}$

ossa intenção neste trabalho é refletir sobre a análise de atividade no campo da Terapia Ocupacional, considerando este procedimento como estratégia de construção de um olhar voltado para a ação humana. Iniciaremos o texto tratando da experiência visual do mundo e da diferenciação entre olhar e visão. Em seguida, examinaremos a participação da análise de atividade na construção do olhar do terapeuta ocupacional para, por fim, propor a invenção, no campo da Terapia Ocupacional, de formas de se fazer análise de atividade que contribuam para a construção de um olhar que possa oferecer acolhimento aos sujeitos em atividade e se deixar afetar por esses sujeitos e por seus fazeres.

\section{A experiência visual do mundo}

Acordamos todos os dias e a primeira coisa que fazemos é abrir os olhos. Com este ato buscamos nos assegurar do mundo, nos orientar em relação ao espaço, retomar nosso lugar na materialidade daquilo que nos rodeia. Ao abrir os olhos, estamos também reativando todos os sentidos e convidando nosso corpo para a experiência, a cada dia renovada, do encontro com o mundo.

Como nos diz Berger (1987, p. 11):

A vista chega antes das palavras. A criança olha e vê antes de falar. Isto é também verdadeiro noutro sentido; (...) explicamos o mundo com palavras, mas as palavras nunca podem anular o fato de estarmos rodeados por ele.

A visão estabelece nosso lugar no espaço do mundo, nos situa, nos localiza e nos permite tomar distância em relação às coisas que o habitam. Para nós, videntes contemporâneos, o cotidiano é marcado por aquilo que vemos, pela forma como vemos e pela articulação dessa experiência visual com as outras sensações que ininterruptamente invadem nosso corpo. A maioria das informações que recebemos nos vem por imagens. Somos seres predominantemente visuais.

Mas, é importante que lembremos, o fato de vermos antes de sabermos falar e de as palavras nunca substituírem por completo a função da vista não significa que esta seja uma pura reação mecânica a determinados estímulos. Aprendemos a ver todos os dias, através de nossas experiências e da relação complexa entre todas as informações sensoriais e proprioceptivas que nos chegam, articuladas ainda, às emoções e sentimentos que as acompanham. Aprendemos a ver nos movimentando, utilizando todo o nosso corpo.
Assim é para um bebê que move sua mão e, de repente, a encontra em seu campo visual, sem saber de onde vem aquela imagem que se posta diante de seus olhos; imagem que é acompanhada de uma sensação corporal, proprioceptiva, ainda não decodificada e significada. $\mathrm{O}$ bebê está a construir seu mundo. Um mundo que já estava aí, mas que ele o encontra, recriando-o a cada vez, através de uma enorme tarefa de aprendizado, que é também uma operação criadora.

Sobre isso Sacks (1995, p. 141) diz:

Passamos a vida aprendendo a ver. O mundo não nos é dado: construímos nosso mundo através de experiência, classificação, memória e reconhecimento incessantes. (...) a maioria de nós não faz a menor idéia da enormidade dessa construção, já que a desempenhamos inconsútil e inconscientemente, milhares de vezes todos os dias, num piscar de olhos.

Essa construção não se dá em isolamento. Ela é atravessada por um campo simbólico no qual cada um de nós está imerso e que nos oferece ferramentas para realizá-la. Isto faz com que a percepção visual não seja somente uma ação fisiológica, mas seja também cultural e subjetiva. Somente vemos aquilo sobre o que nos debruçamos. Somente nos voltamos para aquilo que podemos ver de acordo com o campo de visibilidade que é o nosso. Aquilo que pensamos do mundo e o modo como o entendemos afeta o modo como o vemos e o que vemos.

Uma experiência que exemplifica essa idéia é a de Darwin ao chegar à costa da Patagônia com um grande navio, o Beagle. Depois de ancorado o navio, um grupo se dirigiu para a terra em pequenos botes. E o que Darwin observou foi espantoso: os nativos patagônios, que acompanhavam a chegada dos barcos da costa, eram cegos para o grande bergantin, embora pudessem ver com facilidade os pequenos botes. Isso porque se canoas constituíam uma parte rotineira de sua vida, eles não tinham nenhuma experiência anterior com enormes embarcações. Seu universo de conhecimento interferiu na sua percepção, produzindo um campo de visibilidade e, ao mesmo tempo, elegendo aquilo que para eles estava situado no espaço do invisível (DOSSEY, 1982, p. 78).

Da mesma forma, aquilo que sabemos hoje ou os valores que depositamos nas coisas afetam o modo como as vemos. A experiência visual no mundo contemporâneo é marcada por um bombardeamento contínuo de imagens: televisão, vídeo, cinema, revistas, out-doors veiculam incessantemente imagens em profusão, destituídas de sentido e desconectadas de nossa existência cotidiana. Imagens de coisas, idéias e 
formas de vida que parecem estar ao alcance de todos e que são, ao mesmo tempo, inatingíveis - tão perto, tão longe. Essa experiência excessiva, somada ao aspecto ininterrupto do ato de ver, faz com que o banalizemos e o realizemos de forma tão automática que não chegamos a atentar de fato para aquilo que nos impregna a retina, nem nos damos conta da complexidade que envolve a construção visual do mundo. É como se ficássemos cegos para a eterna novidade do mundo.

Podemos continuar vendo, mas perdemos a capacidade de olhar atentamente para cada coisa e nos encantar com as pequenas percepções; aquelas que se dando nos limiares e nas fronteiras do campo de visibilidade, têm a capacidade de intuir o invisível de cada configuração.

Essa abertura para as pequenas percepções que emanam do invisível é o que alguns artistas dizem buscar numa experiência primordial de ver o mundo com olhos de criança. Como nos ensina Matisse (1953, p. 12), para pintar uma rosa é preciso primeiro esquecer todas as rosas já pintadas, vê-la como se fosse pela primeira vez e buscar sua verdade nessa visão que é também revelação. A pintura se dá, assim, numa experiência que é simultaneamente de encontrar a rosa e criar uma rosa, diferente de todas as outras e que porta a marca de singularidade daquele que a criou.

Aqui se está falando de uma percepção visual que produz e que constitui um olhar criativo, pois como nos ensina Ostrower (1988, p. 167), no ato de perceber, o ser humano já está tentando interpretar e, já começa, assim, a criar. Não existe um momento de compreensão que não seja ao mesmo tempo criação. Por que olhar o mundo é, simultaneamente, sair de si e trazer o mundo para dentro de si.

O olhar é, então, janela da alma e espelho do mundo. "Os pintores costumam dizer que, ao olhar, sentem-se vistos pelas coisas e que ver é experiência mágica" (CHAUÍ, 1988, p. 34). Mágica porque os olhos estão no limite entre materialidade e espiritualidade; entre a visão material do mundo e a captação das forças que o compõe e engendram.

Mas parece haver uma disparidade entre a idéia de uma visão que só vê aquilo para o qual está preparada e um olhar que capta forças para além do que já se sabe e já se espera. Neste percurso em busca de compreender a experiência visual, vamos aos poucos nos dando conta de uma diferença que se insinua entre uma certa idéia de visão e uma outra que vai se construindo em relação ao olhar. Vejamos esta diferença mais de perto.

\section{Olhar e visão}

A modernidade buscou esquadrinhar o olho e as coisas visíveis, com o intuito de excluir da experiência perceptiva tudo que fosse da ordem do invisível, separando aquilo que é objetivo e pertence à realidade, daquilo que é da ordem da subjetividade e pertence àquele que olha. Provocou, assim, uma cisão entre a visão e o olhar (CHAUÍ, 1988, p. 54).

Gil (1996) diferencia esses dois termos dizendo que o olhar implica uma atitude na qual nos pomos não apenas em posição de ver, mas numa participação e integração com aquilo para o qual nos dirigimos. Ao olhar, participamos "do espetáculo total da paisagem" e nos relacionamos ativamente com cada um de seus elementos (GIL, 1996, p. 48). Assim, a distância que a visão impõe entre o sujeito que vê e aquilo que é visto se dissolve na experiência do olhar.

O olhar é pensado aqui, na esteira de MerleauPonty (2004), para além dos processos fisiológicos e os princípios mecânicos e funcionais, como exterioridade e interioridade, laço que nos enlaça às coisas. Este "enlaçamento" só é possível porque o olhar está enraizado na corporeidade enquanto sensibilidade e motricidade. O sentido da experiência visual está, portanto enraizada no corpo vivo e se estende a todo o mundo sensível.

"Meu corpo móvel conta com o mundo visível, faz parte dele. Por outro lado, também é verdade que a visão depende do movimento. Só se vê o que se olha" (MERLEAU-PONTY, 2004, p. 16).

O corpo que olha é uma entre as coisas do mundo, algo que pode ser percebido, mas também, algo que se sente ao sentir que sente, porque é visível e vidente, sensível e senciente ao mesmo tempo. E se o corpo é uma entre as coisas do mundo, a visão se faz no meio delas e não de fora delas. Aquele que olha não é estranho ao mundo que olha, mas coextensivo a ele. As coisas, por sua vez, são configurações abertas que se oferecem ao olhar sob o modo do inacabamento, pois nunca nossos olhos verão todas as suas faces de uma só vez. As coisas são, portanto, visíveis tecidos de invisibilidade (BOSI, 1988, p. 81).

E o olhar não se limita a ver o visível. Ele interroga, pesquisa, penetra e interfere nas coisas e em seus movimentos. O olhar cria sentido para aquilo sobre o qual se debruça e devolve este sentido. Assim, para Gil (1996), enquanto a visão é um ato marcadamente perceptivo, o olhar seria um ato mais que perceptivo, expressivo, e articular-se-ia às linguagens não verbais. O olhar é, nesta perspectiva, expressão de estados de espírito que ainda não podem ser nomeados e que se refletem numa linguagem não-verbal, destituída de signos, porém apta a lançar e captar forças, sinais ínfimos, quase invisíveis Trata-se de uma 
linguagem das percepções sutis que procuram seu caminho para a expressão (GIL, 1996, p. 50).

Entre todas as outras coisas sobre as quais se debruça nosso olhar encontrará outro olhar, este também vidente e visível, este também incrustado num corpo e mergulhado no mundo vivido. "Olhar é antes do mais olhar um olhar. Se o olhar não olhasse um olhar, apenas veria. Mas se olha, é porque espera um movimento de retorno" (GIL, 1996, p. 48).

Assim, quando olhamos um outro, podemos, ao mesmo tempo, ver um olhar outro e nos ver refletido em seu olhar. Aquilo que vemos no outro não são os traços objetivos de um rosto, mas a força intensiva que o configura, seu movimento e sua expressividade; mas vemos também o reflexo de nosso olhar no olhar do outro, a nossa não objetividade, aquilo que em nós é invisível e imaterial.

Nesta interação, nunca recebo de alguém a imagem exata do meu olhar, mas um olhar que expressa uma certa maneira de receber meu olhar e o responder. O olhar do outro não me abarca inteiramente porque nem sua visão nem a minha nos constituem como objetos definidos e terminados. O olhar envolve, apalpa, cria atmosferas e capta pequenas percepções, "como se a vocação do olhar fosse articular o visível numa quase-linguagem, para melhor comunicar o invisivel por contacto e fluência" (GIL, 1996, p. 53).

Podemos depreender daí que se a visão é delimitada pelo campo de visibilidade de uma dada configuração histórica, o olhar, ao penetrar e integrar-se à paisagem sobre a qual se debruça, atravessa este campo de visibilidade em direção às suas margens, captando as cintilações do invisível.

Mas o que tudo isso tem a ver com a Terapia Ocupacional e sua análise de atividades?

\section{ocupacional}

\section{A construção do olhar do terapeuta}

Em Terapia Ocupacional buscamos estabelecer um processo terapêutico a partir de um encontro que se dá com o nosso usuário através da realização de atividades. Para que possamos propor atividades, no sentido de promover um processo transformador de uma dada situação, é preciso, segundo Ferrigno (1990, p. 222), que tenhamos analisado previamente essas atividades. De uma maneira geral, isto significa que o terapeuta ocupacional precisa conhecer as atividades, estudá-las, observar seus componentes, as técnicas, os movimentos, as habilidades e as capacidades envolvidas.

Existem, no campo da Terapia Ocupacional, diversos modelos de análise de atividades que nos orientam no sentido de empreender esse estudo. No entanto, não podemos nos esquecer que os modelos de análise de atividade inserem a atividade em uma dada concepção de homem, saúde e sociedade. Por isso temos que ter em mente, como nos ensina Medeiros (2003, p. 152), que as diferentes formas de analisar uma atividade são diferentes formas de ver o mundo e carregam consigo já uma interpretação.

Porém, uma análise de atividade faz mais do que expressar diferentes formas de ver o mundo, ela produz uma forma de ver. Alguns autores, inclusive, explicitam a intenção de que os modelos de análise por eles propostos se constituam em instrumentos de treinamento para que os terapeutas ocupacionais possam selecionar atividades mais apropriadas terapeuticamente (TROMBLY; SCOTT apud BENETTON, 1994, p. 25).

É neste sentido que entendemos que, em Terapia Ocupacional, a análise de atividade tem a função de construir a forma como o terapeuta ocupacional poderá perceber o fazer humano. Diferentes tipos de análises produzirão diferentes tipos de olho, alguns que só vêem, outros que podem olhar.

Ao se propor a ser uma estratégia de treinamento para que o terapeuta ocupacional seja capaz de identificar o que cada atividade envolve de desempenho motor, perceptual, cognitivo ou os aspectos psicodinâmicos presentes em sua realização, muitos dos modelos de análises de atividades que encontramos na literatura de Terapia Ocupacional, dividem uma atividade em seus mínimos componentes. Este procedimento acaba por fragmentar a atividade, dificultando a integração daquilo que é percebido, e terminando por fragmentar também o fazer do paciente e o olhar que se debruça sobre este fazer.

Este tipo de análise aprisiona o olhar no visível, isto é, produz um olho que, treinado, só decodifica no que vê aquilo que já conhece, gerando um processo contínuo de re-conhecimento do que é visto e sua posterior classificação numa grade teórica dada a priori.

E se o terapeuta não é capaz de olhar, mas apenas de ver, estará apto somente a fornecer diagnósticos para determinadas situações e, a partir deles, propor um plano de tratamento previamente estabelecido. Não será capaz de entrar num espaço de troca com seu usuário, no qual este, como agente do processo, colocará constantemente enigmas para seu terapeuta.

Se o que marca o advento da clínica na modernidade é uma mutação do olhar que o torna prisioneiro de um visível inteiramente passível de articulação a uma linguagem positiva, na qual todos os signos podem ser compreendidos por uma grade de sentidos 
previamente construída (FOUCAULT, 1998), uma clínica que se desprenda das amarras da modernidade e de sua intenção de tudo ver, decifrar e significar deverá se pautar sobre a construção de um outro olhar, que comporte zonas de obscuridade em relação às quais nada se pode saber.

Nesta outra clínica da terapia ocupacional, para que uma comunicação se estabeleça é fundamental que se possa escutar e olhar a ação do paciente no mundo, acolher esta ação, que é de qualquer forma expressiva e diz alguma coisa, mesmo que ainda não seja possível nomear aquilo que é dito.

Assim, ao olhar alguém que faz alguma coisa, devemos buscar ver, não um fator de cada vez, mas a relação entre eles e deles conosco. Buscar uma percepção que não opere em isolamento, mas que esteja sempre ligada ao movimento, ao conjunto das sensações que habitam nosso corpo a cada momento e ao nosso interesse em conhecer e explorar o mundo.

E mais, ao olhar alguém realizar alguma atividade já estamos nos relacionando com ele, interferindo nesse fazer e estamos também sendo olhados. Esta relação é de interferência mútua, somos estimulados e estimulamos.

"Olhar um olhar é receber dele uma impressão, acolhê-lo de uma certa maneira e mostrá-lo ao mesmo tempo, reagir através de um outro olhar ao olhar que recebemos" (GIL, 1996, p. 50).

Olhar e ser olhado exercem-se em um campo de forças no qual intervir e conhecer estão presentes. Estamos imersos num jogo de interferências que pode ser de troca, comunicação e estímulo à criação; mas também pode penetrar no ser olhado, ferindo-o, tolhendo sua liberdade.

A atenção e o cuidado do terapeuta ocupacional com a forma como uma atividade é realizada, o olhar que dedica àquele que a realiza, pode colocar esta atividade e esta forma de fazer ao seu alcance: possibilita-lhe pensar os possíveis sentidos desta atividade para quem a realiza, porque ela é feita, como é feita, em que situação. Mas aqui já não se trata de um sentido previamente determinado, mas um sentido construído no encontro, no interior do processo terapêutico. Nesta perspectiva, olhar torna-se sinônimo de cuidar, zelar. Constitui, enfim, um ato de acolhimento. Um acolhimento que só poderá se dar se for considerada a existência de uma zona de não-sentido e de invisibilidade que permite a integridade da ação.

Quando propomos a um usuário que faça uma atividade ou quando procuramos junto com ele novas formas de estar e agir no mundo, devemos estar atentos para o fato de que uma ação articula infinitas linhas, al- gumas que re-enviam à história do sujeito, outras de diferenciação e invenção. E mais, uma ação se dá a partir de um corpo no qual todas essas linhas estão articuladas.

Neste sentido, assim como o artista, o terapeuta ocupacional também precisa se "ocupar" da percepção e buscar nas imagens mais cotidianas e mais comuns aquilo que nelas há de inusitado, de novo, de diferente, de interessante, de singular. Para isto talvez seja preciso pensar, agir e olhar no cotidiano como o faria um estrangeiro: estranhar e se encantar com cada nova revelação.

É justamente esta possibilidade de encantarse com aquilo que é mais sutil, que é preciso ativar no olho do terapeuta ocupacional, para que seja possível abandonar a visão, que só encontra aquilo para o qual está preparada, e se abrir para uma experiência do olhar que encontra um outro olhar, se deixa afetar por ele e pode assim, conectar-se às impressões que estão no limiar de um certo campo de visibilidade. Esta ativação poderá se dar através da construção de um olhar próprio, trabalho árduo que inclui um processo duplo de construção e desconstrução no qual tentamos nos despir daquilo que pode fazer nosso olho ver apenas o que já era esperado ou sabido. Se todas as rosas já vistas vão impregnar nossa visão a cada nova rosa que encontrarmos, e se são tantas as rosas já vistas, é preciso esforço e coragem para abandonar essas visões prévias e privilegiar a experiência viva da percepção no instante em que ela acontece.

Esta percepção viva, capaz de acessar sensações ínfimas, está em íntima conexão com a experiência estética e acompanha necessariamente a apreensão de uma forma visual, sonora, gestual. Neste sentido entendemos que a arte é um poderoso aliado para ativar este olhar aberto às pequenas impressões e que se deixe contaminar pela potência de invenção presente no ato mais trivial e cotidiano.

Só através de um olhar conectado e contaminado pelas pequenas percepções será possível acolher aquilo que nos é estranho e, aceitando-o, oferecer a ele um lugar no mundo compartilhado.

\section{CONCLUSÃO}

Para concluir, gostaríamos de propor a idéia de que, se quisermos ativar um outro olho no terapeuta ocupacional, um olho atento a cada detalhe e que se sabe criador de novas configurações, entendendo que a percepção está intimamente ligada à análise daquilo que é percebido, mas também à expressão, será preciso inventar uma outra análise de atividade, que se coloque em oposição àquelas que fragmentam a um só tempo as atividades, os agentes e os terapeutas. 
Uma contribuição interessante que pode nos ajudar a pensar esta outra análise de atividades é a de Benetton (1994). Fazendo uma crítica dos modelos de análise que produzem "uma divisão que poderia seguir ad infinitum, atomizando de tal forma as atividades que as esvazia de significados pessoais e sociais" (BENNETON, 1994, p. 27), esta autora nos propõe a constituição de um Laboratório de Análise de Atividades, "lugar onde ocorre a experiência do fazer" (BENNETON, 1994, p. 29). O Laboratório seria, então, o espaço no qual o terapeuta teria a oportunidade de fazer uma determinada atividade para que, num momento posterior, pudesse refletir e elaborar essa experiência, através da discussão das técnicas, da criatividade, do produto e das emoções e sentimentos individuais envolvidos.

Nesta perspectiva, o primeiro passo em uma análise de atividades é a decodificação dos investimentos afetivos daquele que a realiza, seu jeito de fazer, suas reações a determinados materiais ou técnicas, suas habilidades e dificuldades. Assim, o olhar se volta, neste primeiro momento, para uma observação de si próprio e dessa experiência singular para depois ser ampliado para a visão do processo dos colegas e a discussão final onde essas experiências são coletivizadas e ressignificadas, sempre mantendo a marca primeira que nos diz que cada vez que realizamos uma atividade é única e singular.

$\mathrm{Na}$ construção desta outra análise de atividade, estudar os diferentes modelos de análise de atividade no campo da Terapia Ocupacional teria a dupla função, seguindo a proposta de Medeiros (2003), de nos possibilitar a compreensão da concepção de mundo que elas trazem e de se constituir em subsídio para construir nossa própria forma de olhar, buscando nosso olhar criativo e singular, sabendo que, ao fazê-lo, estamos assumindo uma perspectiva que é a nossa, e que não é neutra e nem isenta de conceitos e valorações.

Como nos ensina Sacks (1995, p. 149),

os processos perceptivos-cognitivos, enquanto fisiológicos, também são pessoais - não se trata de um mundo que a pessoa percebe, mas de seu próprio mundo - e levam a, estão ligados a, um eu perceptivo, com uma vontade, uma orientação e um estilo próprios (1995, p. 149).

Por fim, esta outra análise de atividade, a ser constantemente inventada, teria que levar em conta que, para além da análise da "atividade em si" - o material utilizado, as técnicas envolvidas, as habilidades e os movimentos que são requeridos para sua realização, o contexto sócio-cultural em que é realizada -, temos que pensar que esta atividade virtual só se atualiza na ação de um sujeito que a realize. Estamos sempre diante de alguém que empreende uma ação e desenvolve uma forma de fazer. Sendo assim, esta outra análise de atividade conteria um componente inalienável de singularidade e teria que estar atenta ao movimento criativo onde quer que ele apareça, pois implicaria a análise de um fazer sempre singular e a abertura para infinitas maneiras que este fazer possa ganhar.

Pintar envolve a coordenação motora fina das mãos, mas há quem pinte com os pés, há quem pinte com a boca. Fotografar implica um trabalho em torno da percepção visual, mas há fotógrafos cegos. Aí está a grande riqueza do trabalho do terapeuta ocupacional: possibilitar a cada um a descoberta de uma forma própria de construir sua ação no mundo. Deste ponto de vista, mais do que aprender sobre as características de cada atividade, o que esta outra análise de atividade pode nos ensinar é a olhar para nós mesmos em nossas ações e em nosso fazer; a olhar para o outro em suas ações e buscar aí, no limiar do invisível, a intrincada trama de afetos, histórias e saberes; e a olhar para cada atividade em suas infinitas possibilidades, incluindo a abertura para o futuro de novas experiências com os materiais, com as técnicas, com a cultura e com o mundo humano.

Enfim, iluminando nossa reflexão com a lição de Merleau-Ponty (2004), podemos aprender com a experiência estética que pode estar contida nesta outra análise de atividade, a acolher generosamente em nós mesmos o mundo, essa misteriosa realidade que é, ao mesmo, tempo familiar e cotidiana.

LIMA, E. M. F. A. Activity analyses and the perception of the occupational therapist. Rev. Ter. Ocup. Univ. São Paulo, v. 15, n. 2, p. 42-8, maio/ago., 2004.

ABSTRACT: This paper focuses on the discussion about the activity analyses in the occupational therapy's field and its role in the process of structuring the occupational therapist's perception of the human action and people in activity.

KEY WORDS: Occupational therapy/trends. Perception. Human activities. 


\section{REFERÊNCIAS}

BENETTON, M. J. A terapia ocupacional como instrumento nas ações de saúde mental. Campinas: Faculdade de Ciências Médicas da UNICAMP, 1994.

BERGER, J. Modos de ver. São Paulo: Martins Fontes, 1987.

BOSI, A. Fenomenologia do olhar. In: Novaes, A. (Org.). 0 olhar. São Paulo: Cia das Letras, 1988.

CHAUÍ, M. Janela da alma, espelho do mundo. In: NOVAES, A. (Org.). O olhar. São Paulo: Cia das Letras, 1988.

DOSSEY, I. Space, time and medicine. Massachussets: Shambhala Pub., 1982.

FERRIGNO, I. S. V. “O que é terapia ocupacional.” In: KUDO, A. M. (Org.). Fisioterapia, fonoaudiologia e terapia ocupacional em pediatria. São Paulo: Sarvier, 1990. (Monografias Médicas, XXXII).

Recebido para publicação: 28/06/04

Aceito para publicação: 20/08/04
FOUCAULT, M. O nascimento da clínica. Rio de Janeiro: Forense Universitária, 1998.

GIL, J. A imagem-nua e as pequenas percepções - estética e metafenomenologia. Lisboa: Relógio d'Água, 1996.

MATISSE, H. Com olhos de criança. Idéias coletadas por Règine Pernoud. Le Corrier de L'Unesco, v. 2, n. 2/3, jun/set., 1991.

MEDEIROS, M. H. Terapia ocupacional: um enfoque epistemológico e social. São Carlos: Hucitec/ EdUFSCar, 2003.

MERLEAU-PONTY, M. O olho e o espírito. São Paulo: Cosac \& Naify, 2004.

OSTROWER, F. A construção do olhar. In: NOVAES, A. (Org.). O olhar. São Paulo: Cia das Letras, 1998.

SACKS, O. Um antropólogo em Marte: sete histórias paradoxais. São Paulo: Cia das Letras, 1995. 